\title{
ELABORAÇÃO DE PORTFÓLIOS NO ENSINO DE BIOLOGIA COMO ESTRATÉGIA PARA CONSTRUIR APRENDIZADOS SOBRE OS INVERTEBRADOS
}

\author{
ELABORATION OF PORTFOLIOS IN TEACHING BIOLOGY AS A STRATEGY \\ TO BUILD LEARNINGS ABOUT INVERTEBRATES
}

\author{
Monica Strege Médici ${ }^{1}$ \\ ORCID iD: $\underline{0000-0003-2810-8913}$ \\ Marcelo Franco Leão ${ }^{2}$ \\ ORCID iD: 0000-0002-9184-916X
}

\begin{abstract}
RESUMO
O presente texto tem objetivo de descrever como ocorreu a elaboração de portfólios sobre invertebrados por estudantes do $2^{\circ}$ ano do Ensino Médio de uma escola pública mato-grossense, bem como a avaliação dos envolvidos sobre essa atividade didática. Este estudo configura-se como descritivo e exploratório, ocorrido no quarto bimestre letivo de 2019, que envolveu 39 estudantes do $2^{\circ}$ ano do Ensino Médio Turmas A, B e C do turno matutino da Escola Estadual Professora Maria Esther Peres, município de Vila Rica/MT. Dos portfólios elaborados, analisou-se os seguintes critérios: contextualização, fontes confiáveis, conceitos científicos corretos, capacidade reflexiva, forma de expressão (e apresentação) e esquemas satisfatórios. Para coletar dados referentes a avaliação foi utilizado um questionário constituído de 9 questões abertas que possibilitaram identificar as limitações encontradas na elaboração dos portfólios, as potencialidades da atividade tanto como estratégia de ensino que contribui na compreensão dos invertebrados quanto na sistematização da aprendizagem. Logo, o portfólio mostrouse uma estratégia de ensino motivadora, um instrumento de avaliação diferenciado e uma alternativa viável para ser desenvolvida no ensino de ciências por facilitar a construção de aprendizagens sobre os invertebrados.
\end{abstract}

Palavras-chave: Estratégia de ensino. Instrumento de avaliação. Portfólio.

\begin{abstract}
This text aims to describe how the development of portfolios about invertebrates by students of the 2 nd year of high school in a public school in Mato Grosso, as well as the evaluation of those involved in this didactic activity. This study is a descriptive and exploratory study, which took place in the fourth semester of 2019, which involved 39 students of the 2nd year of High School Classes A, B and C of the morning shift of the State School Professor Maria Esther Peres, municipality of Vila Rica / MT. From

\footnotetext{
${ }^{1}$ Graduação em Licenciatura em Ciências Biológicas e Bacharel em Ecologia (Centro Universitário de Várzea Grande). Especialização em Ensino de Biologia (Universidade Candido Mendes). Membro do Grupo de Pesquisa Ensino de Ciências e Matemática no Baixo Araguaia (EnCiMa). Professora efetiva na Escola Estadual Professora Maria Esther Peres onde ministra as disciplinas de ciências e biologia para o Ensino Fundamental e Médio, Vila Rica, Mato Grosso, Brasil. Endereço para correspondência: Rua dos Eucaliptos, 51, Cidade Jardim, Vila Rica, Mato Grosso, Brasil, CEP: 78.645-000. E-mail: stregemonica@ hotmail.com.

${ }^{2}$ Graduação em Química Licenciatura Plena (UNISC) e em Licenciatura em Física (UNEMAT). Especialização em Orientação Educacional (DOM ALBERTO) e em Relações Raciais e Educação na Sociedade Brasileira (UFMT). Mestrado em Ensino (UNIVATES) e Doutorado em Educação em Ciências: Química da Vida e Saúde (UFRGS). Membro do Grupo de Pesquisa Ensino de Ciências e Matemática no Baixo Araguaia (EnCiMa). Professor de Química no Departamento de Ensino do IFMT Campus Confresa, Confresa, Mato Grosso, Brasil. Endereço para correspondência: Rua da Paz., 135, Jardim do Éden, Confresa, Mato Grosso, Brasil, CEP: 78.652000. E-mail: marcelo.leao@cfs.ifmt.edu.br.
} 
the developed portfolios, the following criteria were analyzed: contextualization, reliable sources, correct scientific concepts, reflective capacity, form of expression (and presentation) and satisfactory schemes. To collect data related to the evaluation, a questionnaire consisting of 9 open questions was used, which made it possible to identify the limitations found in the development of portfolios, the potential of the activity both as a teaching strategy that contributes to the understanding of invertebrates and to the systematization of learning. Therefore, the portfolio proved to be a motivating teaching strategy, a differentiated assessment tool and a viable alternative to be developed in science education as it facilitates the construction of learning about invertebrates.

Keywords: Teaching strategy. Evaluation tool. Portfolio.

\section{INTRODUÇÃO}

No contexto atual, uma necessidade para o processo educativo é o desenvolvimento de estratégias e atividades que permitam pesquisas, discussões reflexivas e construção de aprendizagens significativas, tornando o ensino efetivo e de qualidade, inserindo novos métodos ativos que envolvem os estudantes. Essas novas metodologias de ensino vêm ganhando espaço nas salas de aula, o que aos poucos vai substituindo metodologias tradicionais de exposição e memorização, práticas estas defasadas e insuficientes para a formação dos estudantes na contemporaneidade. Nesse sentido, o fazer pedagógico necessita ser um instrumento eficaz para promover mudanças no envolvimento dos estudantes pelo objeto de aprendizagem, de maneira que ocorra o desenvolvimento de habilidades formativas.

No contexto educacional, segundo Gonçalves, Pacheco e Bittencourt (2019), o portfólio é uma incrível ferramenta de avaliação e autorreflexão para os estudantes, um recurso extremamente prático que desenvolve relações entre o ensino e a aprendizagem. Assim, o portfólio é considerado como uma estratégia didática que envolve planejamento, pesquisa, capacidade argumentativa, sistematização dos aprendizados e organização na apresentação do conhecimento construído.

Outro aspecto a ser considerado é que o estudo de zoologia na Educação Básica consiste em um desafio aos professores, pois, as dimensões geográficas dos estudantes nem sempre permitem conhecer os diferentes biomas, bem como a biodiversidade neles existentes. O desafio está em ensinar sobre estruturas anatômicas, fisiológicas e as relações ecológicas dos organismos vivos sem que os estudantes os conheçam fisicamente.

No estudo realizado por Santos e Terán (2013), fica evidenciada a defesa de que o ensino de zoologia terá um resultado melhor se for desenvolvido por meio de outras estratégias e metodologias de ensino que não aquelas tradicionais, limitadas a exposição e execução de tarefas. Assim, buscar novas estratégias metodológicas para o ensino dessa temática, oportuniza 
explorar as potencialidades dos próprios estudantes que assumem o protagonismo da aprendizagem deixando de lado a antiquada 'reprodução de conhecimento'.

Ao considerar a necessidade de reinventar o ato educativo para que sejam atendidos os anseios da atualidade, fica evidente a necessidade do professor adotar práticas pedagógicas diferentes daquelas que ao longo dos anos lhe foram atribuídas. Práticas que endossava o professor como único detentor do saber enquanto aos estudantes restava atuar como expectador da aula e reprodutor de conteúdos nem sempre compreendidos. Essa mudança já vem a tempos motivada por Freire (1996), que critica essa "educação bancária" e acredita numa educação libertadora, capaz de proporcionar ensinamentos efetivos para a vida. Por isso acredita-se que a construção de portfólios possa envolver os estudantes na construção de conhecimentos de uma forma autônoma e emancipatória.

Frente ao exposto, este texto tem como objetivo descrever como ocorreu a elaboração de portfólios sobre invertebrados por estudantes do $7^{\circ}$ ano do Ensino Fundamental de uma escola pública mato-grossense, assim como a avaliação dos envolvidos sobre a atividade pedagógica que vivenciaram.

\section{REFLEXÕES TEÓRICAS SOBRE PORTFÓLIOS}

O cenário educacional, ao longo dos anos vem propiciando mudanças significativas no âmbito do processo de aprendizagem. Assim, os estudantes estão cada vez mais participando ativamente da construção do processo o que melhora, perceptivelmente, o desempenho tanto em atividades desenvolvidas individualmente como naquelas ocorridas de maneira coletiva (ANASTASIOU et al., 2004).

O portfólio pode ser considerado uma compilação dos trabalhos desempenhados por um estudante e/ou profissional da educação. Isto permite ter uma ampla visibilidade do que foi construído no processo formativo, de maneira a compartilhar suas respectivas experiências e qualificações. Por meio do portfólio, os estudantes podem reunir os resultados das pesquisas realizadas de maneira a sistematizar o que construíram ao longo do percurso de estudos (VIEIRA, 2002).

De acordo com Alvarenga e Araújo (2006, p. 139), o portfólio serve como "elemento cognitivo de reflexão ligado à capacidade de síntese de informações, a partir da análise e avaliação". Para as autoras, a característica básica de um portfólio compreende na coletânea de evidências e documentos que sistematizam e registram como ocorreu o desenvolvimento da aprendizagem sobre determinado assunto. Conforme destacam Boas e Freitas (2005), ao 
elaborar seu portfólio, o estudante se torna protagonista no processo de construção de aprendizagens, sendo, inclusive, o responsável pela escolha de seus próprios critérios informativos. Ao descreverem os seus saberes de uma forma clara e consistente, os estudantes são levados a organizar seus próprios aprendizados e isso permite que, ao longo da vida, se tornem seres pensantes e ativos para investigar e formular suas opiniões.

Ao situar a utilização do portfólio no âmbito educacional brasileiro, percebe-se que o mesmo engloba uma atividade dinâmica e envolvente. Possibilitando, assim, meios de independência sobre as formas tradicionais de avaliação, que persistem em permanecer nas escolas brasileiras e se tornarem maçantes na concepção dos estudantes . Ademais, o portfólio pode ser compreendido como "procedimento metodológico que permite envolver atividades didáticas de autoavaliação que documentem aspectos multidimensionais do que os alunos aprenderam" (BEHRENS, 2006, p. 105).

O precário sistema de avaliação da rede pública, prioriza atribuir notas que definem os estudantes em bons ou ruins. O portfólio, por sua vez, permite quebrar esse paradigma, pois considera todo o processo de construção de saberes como importante e permite constatá-lo de maneira organizada e cronológica (COTTA et al., 2012).

Como relatado por Ambrósio (2013), o portfólio vai além de uma simples metodologia ativa por se constituir de um ato significativo de reflexão do próprio contexto educacional brasileiro. De acordo com o autor, ele ainda não é comum e peculiar dentre os novos métodos de avaliação. Muitos professores ainda resistem ao instrumento devido exigir acompanhamento do desenvolvimento dos estudos e da elaboração dos relatórios que exibem uma descrição detalhada sobre o que foi compreendido por cada estudante.

Mesmo exigindo tempo e dedicação dos professores, o portfólio é uma estratégia de ensino e ao mesmo tempo um instrumento de avaliação da aprendizagem satisfatório. Ele permite o olhar interrogativo ao processo educativo e serve como parâmetro para constatar se ocorreram as aprendizagens esperadas. Além disso, o portfólio traz um viés de inovação, com uma sistemática que permite aos estudantes serem mais criteriosos no momento de executar a organização detalhada de suas aprendizagens (CARVALHO, 2007).

O estudo desenvolvido por Carvalho (2007), enquanto estratégia de ensino, considerou a utilização do portfólio como motivadora por envolver os estudantes de maneira evidente. Como instrumento de avaliação foi adequado e satisfatório frente aos objetivos que a autora tinha estabelecido. Assim, o portfólio pode ser adotado como instrumento avaliativo na perspectiva de uma avaliação formativa (também designada avaliação processual ou contínua) por ser um ato permanente pelo qual o professor reflete toda a trajetória educativa enxergando 
a avaliação do processo de construção da aprendizagem e não como um fim ou apenas um resultado em si.

Carvalho e Porto (2005, p. 17) sugerem que "O portfólio educacional é o produto de um processo autorreflexivo, contínuo e documentado de formação e de avaliação”. Importante destacar a importância da avaliação para os estudantes e para o professor. É importante transformar este momento em uma oportunidade de refletir sobre o processo educativo e como se estabelecem o ensino e a aprendizagem.

Essa reflexão é necessária, mesmo porque os conceitos científicos não são memorizados ou assimilados devido a transmissão de saber realizada em uma aula expositiva (VIGOTSKY, 2000). Ressalta, também, que os conceitos se constituem em face do confronto entre todas atividades propostas com pensamento individual. Assim, é possível dizer que a assimilação dos conceitos científicos se forma no processo de aprendizagem e distinguem-se dos espontâneos devido a relação da experiência do indivíduo. A formação dos conceitos científicos apenas começa no momento em que o estudante se aproxima de um significado novo. Nesse sentido, a educação precisa ser veículo do conceito científico e o estudante inserido neste processo tem a autonomia para consolidar ou não o conceito científico.

Nessa perspectiva, é preciso romper definitivamente com qualquer ideia de que avaliar se restringe apenas a um olhar dos professores sobre os estudantes e se isso expressa, de fato, o que estes conhecem (FREIRE, 1997). Segundo o autor, a avaliação formativa está pautada na continuidade do processo educativo, focada no porvir. Deste modo, acredita-se que é ao longo do processo que o professor pode redimensionar o planejamento enfatizando seu resultado.

Dessa forma, a avaliação permeia todo o processo de aprendizagem e não se restringe a apenas um instrumento ou momento para ocorrer, o indicado é que ela ocorra de diferentes maneiras (HADJI, 2001). Essa discussão sobre a avaliação da aprendizagem é levantada por se entender que a elaboração de portfólios pode ser um instrumento adequado para que os estudantes expressem seus aprendizados sobre os invertebrados.

Além do mais, Hadji (2001, p.131) alerta que:

A avaliação não pode ser usada como arma do avaliador para coagir e manipular o aluno frente à autoridade que lhe é conferida. Para evitar incorrer nessa armadilha, o professor pode se valer de técnicas para aproximar-se da ação de avaliar em sua essência, na constituição de uma ética do agir avaliativo.

Deste modo, o uso de portfólio é um instrumento que busca a essência da avaliação da aprendizagem, pois amplia a possibilidade de os professores realizarem uma avaliação coerente com aquilo que é ensinado. Assim, proporciona-se compreensões e reflexões enriquecedoras 
para o processo efetivado em aula. Contudo, antes de mais nada, os professores necessitam compreender como a elaboração de portfólios pode ser explorada em suas aulas de maneira a proporcionar um cenário colaborativo, de protagonismo estudantil para torná-los sujeitos críticos e pensantes.

Uma primeira intervenção pedagógica encontrada foi a realizada na disciplina de Biologia em uma escola pública do Estado do Paraná (DIAS JUNIOR, 2014). A prática de ensino propôs a elaboração de portfólios e se mostrou promissora. Além do desafio de proporcionar algo inovador e envolvente para os estudantes do Ensino Médio, essa proposta pedagógica apostou nos portfólios como um instrumento avaliativo eficaz para constatar os aprendizados construídos.

Na oportunidade, os estudantes tiveram que elaborar seus próprios portfólios de maneira a sistematizar os estudos que realizaram sobre os conceitos da Biologia. Mesmo com a inexperiência e o desconforto de realizar esse novo instrumento avaliativo, a atividade também serviu para abandonar práticas viciosas como, por exemplo, a de simplesmente copiar e colar conceitos e informações contidas na internet. Assim, o papel do professor foi imprescindível como mediador, indicando caminhos aos estudantes e apontando ajustes necessários, conduzindo-os a explorar a imaginação e ser protagonista do próprio saber (DIAS JUNIOR, 2014)

Outro estudo similar foi desenvolvido em duas escolas públicas estaduais do estado do Rio de Janeiro, ambas com o intuito de promover o portfólio como instrumento de avaliação no ensino das Ciências Exatas (NASCIMENTO; RÔÇAS, 2015). A proposta visou promover autonomia e interação individual do saber. Ao todo foram 29 estudantes participantes dessa prática avaliativa, que visou diversificar o método tradicional de ensino, explorando a elaboração de portfólios como instrumento moderno e articulado para uma melhor compreensão dos saberes produzidos.

Esse instrumento avaliativo permitiu que os estudantes aprendessem de forma dinâmica e criativa, pois puderam expor suas experiências e percepções construídas no decorrer do processo educativo. Assim, o portfólio possibilitou que eles mostrassem as características próprias de suas aprendizagens, que foram possíveis perceber pelo registro e o relato de cada atividade que realizaram (NASCIMENTO; RÔÇAS, 2015).

Outro estudo que envolveu o assunto partiu do desafio de encontrar novos métodos avaliativos capazes de romper as práticas viciosas e engessadas que estudantes possuem para expressar seus saberes. Nessa ocasião, o uso de portfólios foi apresentado como uma nova perspectiva, que necessita partir dos professores e estudantes, e isso pode levar um tempo para 
se tornar algo concreto. Foi então proposta a atividade na formação de 120 estudantes, futuros profissionais da saúde, os quais elaboraram portfólios como forma de avaliação da aprendizagem (FUENTES-ROJAS, 2017).

Na ocasião, inicialmente ocorreu resistência por parte dos estudantes, pois o tema para realização do estudo era livre. No entanto, todas as informações deveriam estar embasadas e as ideias apresentadas de forma lógica e articulada. Viabilizando apresentar as recordações, mostrar as experiências estratégicas e relatar os saberes possibilitados (FUENTES-ROJAS, 2017).

Cabe ressaltar que, mesmo o portfólio sendo uma estratégia de ensino e instrumento de avaliação que vem ganhando espaço nas práticas educativas entre os professores brasileiros, ainda é possível encontrar forte presença da avaliação tradicional nas escolas. Por vezes essas práticas obsoletas são exigidas pelos próprios estudantes, acomodados ou temerosos, que resistem a métodos mais dinâmicos e complexos, a exemplo dos portfólios.

\section{METODOLOGIA}

O presente estudo configura-se como descritivo e exploratório, de abordagem qualitativa. Optou-se por esse tipo de abordagem devido considerar a subjetividade do contexto em que ocorreu a elaboração de portfólios como instrumento didático para o estudo dos invertebrados. Trata-se da investigação de uma experiência pedagógica, ocorrida no $4^{\circ}$ bimestre letivo de 2019, mais especificamente nos meses de novembro de 2019 a janeiro de 2020.

Os sujeitos investigados compreendem os 39 estudantes de $2^{\circ}$ ano do Ensino Médio, turmas A, B e C devidamente matriculados no período matutino da Escola Estadual Professora Maria Esther Peres, município de Vila Rica/MT.

O assunto escolhido para a atividade foi a 'Evolução dos Invertebrados'. Em sala de aula, foi realizada a exposição teórica das características gerais dos invertebrados, no intuito de aproximar os estudantes das terminologias específicas necessárias para compreender o assunto. Após essa apresentação dos conceitos âncoras, os estudantes tiveram a oportunidade de dialogar e sanar suas dúvidas. Foi então proposta a elaboração dos portfólios, de maneira individual, que consistia em pesquisar, descrever e esquematizar a anatomia interna e externa de um organismo de cada filo de invertebrado, sendo eles: poríferos, cnidários, platelmintos, nematelmintos, moluscos, anelídeos, artrópodes e equinodermos.

A produção desses esquemas foi realizada de forma manual, ou seja, por meio de desenhos, que serviram para ilustrar e posteriormente explicar a fisiologia do animal, 
detalhando cada sistema. Os estudantes também foram motivados a descrever as relações ecológicas dos invertebrados, apresentando a escala evolutiva a cada novo filo. A atividade foi desenvolvida por meio do planejamento, pesquisa e elaboração dos portfólios.

Para a realização da atividade, os estudantes foram orientados a explorar fontes variadas, para além do livro didático, afim de buscar fontes especializadas, como livros, artigos, blogs e outros materiais disponíveis na Web. Em aula, os estudantes compartilhavam as fontes que encontravam e muitas das informações foram analisadas coletivamente, inclusive eles emitiam críticas quando as informações eram desencontradas. Essas discussões serviram de estímulo para que utilizassem somente fontes confiáveis na elaboração dos portfólios.

Baseado nos estudos de Gomes et al. (2010) e Bacci (2015), os portfólios foram avaliados de acordo com os seguintes critérios: contextualização, o uso de fontes confiáveis, conceitos científicos corretos, capacidade reflexiva, forma de expressão e apresentação e esquemas satisfatórios. Após a entrega dos portfólios na data combinada, os estudantes avaliaram a atividade por meio de um questionário, que possibilitou levantar importantes aspectos desse processo.

Esse instrumento de coleta de dados foi constituído por 9 (nove) questões abertas, que permitiram identificar a avaliação da atividade pelos estudantes. Cabe ressaltar que antes da realização da pesquisa a escola foi informada, dos objetivos e métodos, e concordou com a realização da mesma ao emitir uma Carta de Anuência. Por se tratar de uma atividade didática, a escola informou que os pais ou responsáveis desses estudantes assinaram no ato da matrícula o consentimento da participação de seus filhos. No intuito de garantir o anonimato desses estudantes, os nomes foram substituídos por algarismos alfanuméricos da seguinte maneira: E1 (Estudante 1), E2 (Estudante 2), E3 (Estudante 3) e assim consecutivamente.

A metodologia utilizada para interpretar os dados coletados por meio deste questionário foi a análise de conteúdo. Para Bardin (2011), esse método designa um conjunto de técnicas de análise das comunicações visando a obter, por procedimentos sistemáticos e objetivos de descrição do conteúdo das mensagens, indicadores (quantitativos ou não) que permitam a inferência de conhecimentos relativos às condições de produção/recepção (variáveis inferidas) destas mensagens. A autora indica que a utilização da análise de conteúdo prevê três fases fundamentais: pré-análise, exploração do material e tratamento dos resultados: inferência e a interpretação.

Sobre o processo de categorização, foram pré-definidas as seguintes categorias: limitações encontradas na elaboração dos portfólios, potencialidades desse instrumento didático como estratégia de ensino e contribuições para a sistematização da aprendizagem dos 
invertebrados. Essas categorias foram pré-definidas por serem características mencionadas na fundamentação teórica, o que facilita a análise dos resultados. Cabe ressaltar que de cada categoria emergiram subcategorias, que a identificação delas ocorreu por meio da frequência nas respostas fornecidas e que a apresentação dos resultados se deu por agrupamento das respostas semelhantes.

\section{ANÁLISES E RESULTADOS}

Em posse dos 39 portfólios elaborados, foram identificados em quantos deles estavam presentes os seguintes critérios: contextualização, o uso de fontes confiáveis, conceitos científicos corretos, capacidade reflexiva, esquemas satisfatórios e a forma de expressão e apresentação. A Figura 1 ilustra o resultado dessa identificação da presença dos critérios nos portfólios.

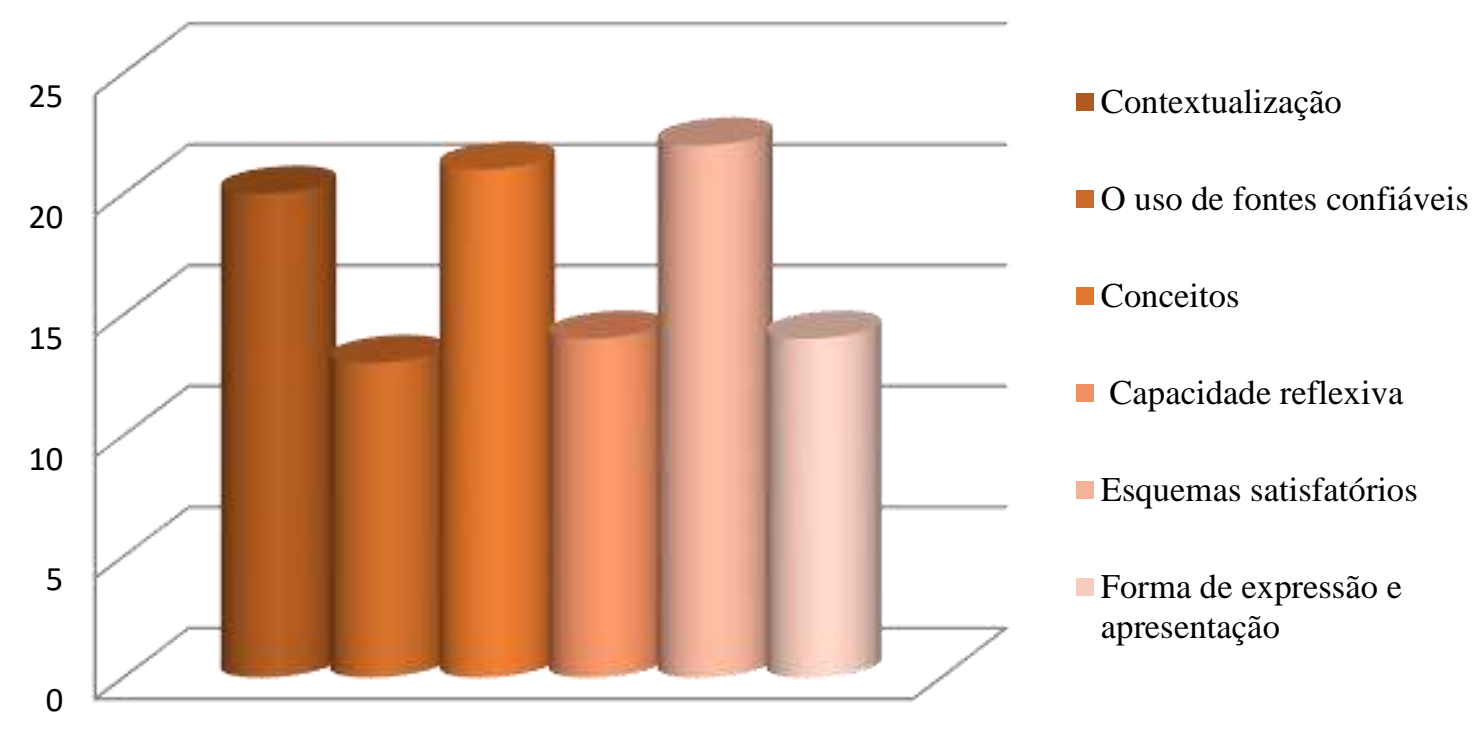

Figura 1 - Quantidade de portfólios que apresentam os critérios escolhidos para análise. Fonte: Dados coletados na pesquisa (2019).

Um primeiro critério utilizado para avaliar os portfólios foi a contextualização, ou seja, verificou-se esse critério estava presente satisfatoriamente nos portfólios no sentido de compreender se a atividade estabeleceu um processo dialógico e interativo importante para a construção de novos saberes. Este aspecto foi observado em 20 portfólios. Para ilustrar este critério, foram selecionados e seguem apresentados os seguintes trechos dos portfólios com apontamentos dos estudantes: 
“Os anelídeos são organismos importantes para a produção de alimentos, pois apresentam capacidade de arar nosso solo com a construção de galerias, além da produção de adubo orgânico, por meio da liberação do húmus" (Portfólio do E7). Observa-se que E7 compreendeu a interação dos organismos estudados com a produção de alimentos.

“O reino animália é composto por seres vivos que podem viver em ambientes diversos: terrestre, dulcícola e marinhos. São organismos que apresentam grande importância para o equilíbrio do meio ambiente, pois tem seu papel na natureza" (Portfólio do E3). Oportunamente o estudante relaciona a importância da diversidade biológica e o equilíbrio do planeta. Seguindo a mesma linha, segue outra colocação: “Os nematódeos realizam a decomposição da matéria orgânica, a degradação de toxinas e a regulação da população de microrganismos e deste modo estimula o desenvolvimento das plantas" (Portfólio do E10).

Geralmente o senso comum associa unicamente nematódeos a parasitas maléficos, como se apenas provocam prejuízos a vida humana. A afirmação de E10, por outro lado, destaca a importância dos nematoides na decomposição da matéria orgânica e sua participação nos ciclos biogeoquímicos. Partindo do pressuposto que a educação necessita promover o diálogo entre os diversos saberes, a contextualização se faz necessária no ensino de ciências, o que foi favorecido pela elaboração dos portfólios, assim como sugerido por Gomes et al. (2010). Bacci (2015) vai além e propõe que os portfólios também favorecem a interdisciplinaridade, ou seja, que a atividade pode envolver as diferentes áreas do conhecimento, o que, segundo o autor, é fundamental para a construção de aprendizagens consistentes e duradouras.

Um segundo critério utilizado para avaliar os portfólios foi a ocorrência, ou não, do uso exclusivo de fontes confiáveis. Ao analisar os portfólios, foi possível observar que este foi o critério menos observado pelos estudantes, uma vez que apenas 13 portfólios foram embasados em fontes confiáveis. Os demais incorreram em um erro comum: a busca de informações em sites diversos sem a devida checagem das fontes. Para ilustrar esta constatação, segue apresentadas as fontes utilizadas no portfólio do E20: "Ciência Hoje, Toda Biologia, Biologia Net, Planeta Bio e o próprio Livro Didático Bio 2, de Sônia Lopes e Sergio Rosso".

A pesquisa escolar requer a adoção de alguns critérios como o uso de fontes de pesquisa confiáveis. Com a democratização das tecnologias digitais existe ampla proliferação de espaços digitais que trazem informações diversas e nem todas apresentam-se de forma confiável. Dias Junior (2014) destaca a importância do professor no sentido de orientar o estudante para que o mesmo possa traçar um itinerário seguro na busca de um resultado satisfatório. Quando o trabalho é embasado em aspectos confiáveis, é possível observar a eficiência da pesquisa no sentido de proporcionar ao estudante informação de qualidade. 
Outro aspecto que foi avaliado nos portfólios foi a apresentação dos conceitos científicos apresentados de forma correta em 21 portfólios. Para exemplificar este critério, seguem os seguintes trechos: "Os poríferos não se locomovem na fase adulta são seres sesseis vivem presos a substratos, podem viver isolados ou em colônia e capturam alimentos por meio da filtragem da água" (Portfólio do E6). Mesmo que o objeto de estudo não faça parte do cotidiano o estudante consegue associar o conhecimento por meio dos conceitos adquiridos durante o desenvolvimento do trabalho.

"Os cnidários são animais exclusivamente aquáticos sendo a maioria marinha e um pequeno grupo vive em ambiente dulcícola" (Portfólio do E9). "Os artrópodes são animais invertebrados que possuem uma característica especial, as patas articuladas, outra particularidade é a presença do exoesqueleto rígido que se locomove dinamicamente devido as patas articuladas. Possuem grande capacidade de adaptação o que resulta na presença de representantes do grupo em todos os ecossistemas do planeta" (Portfólio do E14).

Quando utilizados corretamente os conceitos científicos, amplia-se a possibilidade do estudante realizar a transposição dos mesmos, contribuindo para sua formação integral. Nos portfólios do presente estudo observou-se que a ciência foi abordada como algo útil socialmente, o que demonstra os conceitos selecionados. No estudo realizado por Gomes et al. (2010), os conceitos científicos verificados foram os relacionados a Educação Ambiental. Segundo Vigotsky (2000), a assimilação de conhecimentos científicos só é possível quando imersos no mundo dos objetos de estudo e das interações que eles oportunizam.

Um quarto critério de avaliação dos portfólios, observados em 14 deles, foi se apresentam capacidade reflexiva, ou seja, se os estudantes conseguiram associar os novos conceitos às demais áreas e situações. Em âmbito global, Nascimento e Rôças (2015) apontam que o portfólio assume o perfil de ser um instrumento eficaz no ensino de qualquer componente curricular que pretenda ser capaz de desenvolver seus conteúdos de forma significativa e lógica para os estudantes.

Ainda de acordo com os autores supracitados, a construção do portfólio se constitui em um mecanismo de aprendizagem que pode ser usado para significar o aprendizado oportunizando ao estudante não uma educação mecânica, mas efetiva e construída gradualmente. Essa capacidade reflexiva pode ser ilustrada em parte do Portfólio do E5 "Os invertebrados compõem o maior grupo de animais do planeta, no entanto, sei que existe um grande número de espécies não identificadas devido à escassez de pesquisa nesta área, o que me preocupa, pois a degradação ambiental pode levar a extinção de espécies que sequer foram catalogadas e que são fundamentais para a natureza". 
Percebe-se que E5 traz em sua fala não apenas conhecimento da área de zoologia dos invertebrados, o objeto de estudo central, mas consegue transpor para outras áreas extremamente sensíveis que objetivam a preservação dos componentes bióticos e abióticos existentes no planeta. "Importante estudar os animais a partir de uma linha evolutiva, pois evidencia que a evolução é constante" (Portfólio do E7). Associar os princípios da evolução no estudo dos invertebrados é importante para que o estudante compreenda que todas as espécies estão em constante processo adaptativo e, portanto, suscetíveis à seleção natural onde sobreviverão os mais adaptados.

“Os animais invertebrados são organismos multicelulares, heterotróficos, ou seja, são incapazes de produzir moléculas orgânicas" (Portfólio do E11). Quando o estudante compreende a relação entre a ciência e o cotidiano ele passa a se distanciar do cientificismo. Assim, os portfolios trazem uma abordagem diversificada inserindo aspectos multidimensionais do que os estudantes aprenderam (BEHRENS, 2006, p. 105).

Outro critério utilizado para avaliar os portfólios foi se os esquemas foram elaborados de forma satisfatória, de maneira que descrevesse e esquematizasse a anatomia fisiológica interna e externa de um organismo de cada filo de invertebrado. Ao analisar os portfólios, destaca-se que 22 portfólios apresentaram esquemas satisfatórias, assim como os ilustrados na Figura 2.

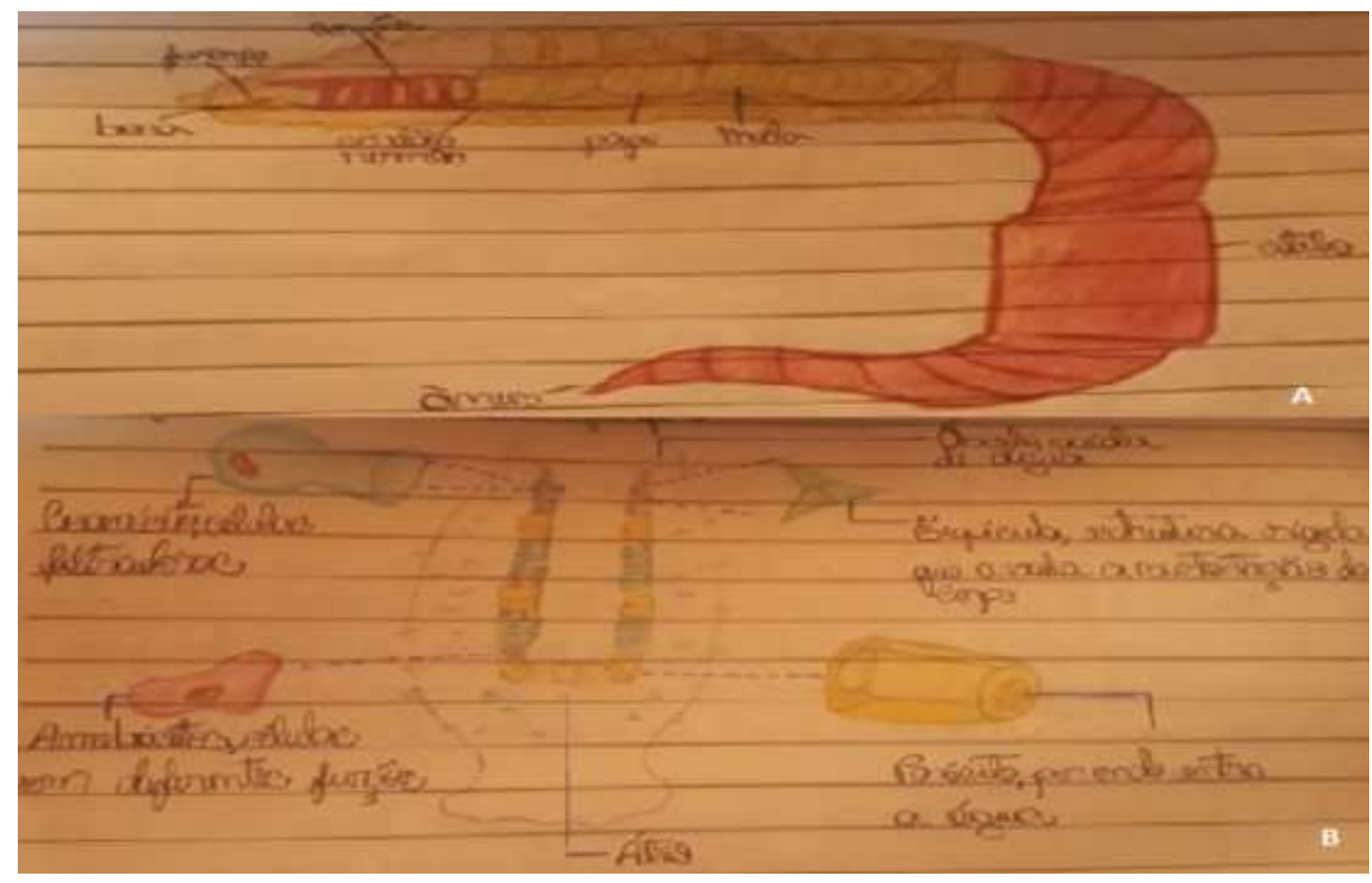

Figura 2 - Esquemas utilizados para representar a anatomia dos invertebrados. Fonte: Dados extraídos do Portfólio do E7 (2019). 
Observa-se nessas ilustrações, a capacidade de sintetizar em forma de desenho, os detalhes da fisiologia interna e externa desses animais. Na Figura 2A é esquematizada a anatomia fisiológica da minhoca, pertencente ao filo dos anelídeos. Já na Figura 2B, o desenho esquematiza a estrutura interna e externa de uma esponja, representante do filo dos poríferos. É notória a riqueza de detalhes expressadas nos desenhos dessa estudante, assim como ocorreu nas representações de outros 21 portfólios. A construção dos esquemas ressalta aspectos multidimensionais, de uso dos recursos e habilidades, para a atividade oportunizando aos estudantes aprender de formas variadas, como destacou Behrens (2006).

Um último critério de avaliação dos portfólios foi a forma de expressão e apresentação. Neste critério, foi observado se as informações pesquisadas foram organizadas de maneira lógica e numa linguagem apropriada na construção de argumentos, ou seja, se articularam os conceitos de maneira coerente e de forma inteligível. Este aspecto foi observado em 14 portfólios em um universo de 39. Para ilustrar o aspecto avaliado, seguem alguns trechos:

“Os cnidários são animais exclusivamente aquáticos sendo a maioria marinha, apenas um pequeno grupo vive em ambiente dulcícola" (Portfólio do E9). "Os artrópodes são animais invertebrados que possuem uma característica especial as patas articuladas, outra particularidade é a presença do exoesqueleto rígido que se locomove dinamicamente devido as patas articuladas. Possuem grande capacidade de adaptação o que resulta na presença de representantes do grupo em todos os ecossistemas do planeta" (Portfólio do E14).

Como afirma Freire (1996, p. 21) é necessário "Saber que ensinar não é transferir conhecimento, mas criar as possibilidades para a sua própria produção ou a sua construção". O autor assegura que é necessário conduzir com intencionalidade as práticas pedagógicas para que o estudante tenha capacidade de construir e consolidar o conhecimento e deste modo ter capacidade de realizar associação entre os saberes formais e informais.

Das respostas emitidas pelos estudantes participantes, foram organizadas três categorias como citado anteriormente, sendo que de cada categoria emergiram subcategorias, conforme esquematizado no Quadro 1.

\begin{tabular}{|c|c|c|}
\hline Categorias & Subcategorias & Fontes/Questões \\
\hline & $\begin{array}{c}\text { Pouco tempo para a } \\
\text { elaboração }\end{array}$ & 1) Quais as dificuldades enfrentadas na construção do \\
seu portfólio?
\end{tabular}




\begin{tabular}{|c|c|c|}
\hline \multirow{3}{*}{$\begin{array}{l}\text { Potencialidades } \\
\text { desse instrumento } \\
\text { didático como } \\
\text { estratégia de } \\
\text { ensino }\end{array}$} & $\begin{array}{l}\text { Facilita a compreensão } \\
\text { do assunto }\end{array}$ & \multirow{3}{*}{$\begin{array}{l}\text { 4) Quais os pontos positivos do uso do portfólio nas } \\
\text { aulas de Biologia? } \\
\text { 5) Em que a construção do portfólio contribui para o } \\
\text { processo de aprendizagem sobre os invertebrados? 6) } \\
\text { Quais os pontos positivos dessa estratégia de ensino } \\
\text { utilizada? }\end{array}$} \\
\hline & $\begin{array}{l}\text { Motiva a busca de } \\
\text { informações }\end{array}$ & \\
\hline & Avaliação diferenciada & \\
\hline \multirow{2}{*}{$\begin{array}{l}\text { Contribuições } \\
\text { para a } \\
\text { sistematização da } \\
\text { aprendizagem dos } \\
\text { invertebrados }\end{array}$} & $\begin{array}{c}\text { Possibilidade de } \\
\text { conhecer características } \\
\text { dos invertebrados }\end{array}$ & \multirow{2}{*}{$\begin{array}{l}\text { 7) De que maneira esta atividade contribuiu para o } \\
\text { aprendizado dos invertebrados? } \\
\text { 8) Quais foram os aspectos relevantes de sua } \\
\text { aprendizagem durante a realização do trabalho? } \\
\text { 9) Considera que o portfólio construído retrata seu } \\
\text { conhecimento sobre os invertebrados? Justifique. }\end{array}$} \\
\hline & $\begin{array}{c}\text { Sistematização dos } \\
\text { conhecimentos sobre os } \\
\text { invertebrados }\end{array}$ & \\
\hline
\end{tabular}

Como é possível perceber, a primeira categoria é referente as limitações encontradas na elaboração dos portfólios. Os dados advindos dos três primeiros questionamentos permitiram identificar as seguintes subcategorias: pouco tempo para a elaboração do portfólio, a extensão do trabalho e o portfólio é considerado uma atividade muito complexa (?).

Uma primeira limitação identificada foi a falta de tempo hábil para que os estudantes elaborassem o portfólio, ou seja, o curto período para a realização da atividade. Algumas respostas que ilustram tal constatação são: “O tempo, como trabalho até as 20 horas tive que encontrar um jeito de conciliar o serviço e o tempo de fazer o trabalho, a maior parte do trabalho fiz no fim de semana" (E3). "O tempo que devíamos administrar com o trabalho e nossas outras obrigações e ainda fazer um modelo de uma das classes dos invertebrados" (E6). "Teve pouco tempo para a construção do portfólio, pois exigia desenhos, pesquisa e a estrutura do trabalho" (E8). "Apesar de ocupar muito tempo, em meu caso, acabou por ser um incentivo do estudo" (E9). "Fiz minhas pesquisas no intervalo das aulas, achei o prazo de entrega muito curto" (E10). "pouco tempo para a realização da pesquisa, sites que, ou não possuíam todos os requisitos, ou conteúdo muito resumido" (E16).

Boas e Freitas (2005), destacam que a proposta da elaboração do portfólio traz o estudante para o centro do processo de aprendizagem possibilitando seu protagonismo e a corresponsabilidade. Uma vez que o estudante passa a adotar os critérios de construção do portfólio, inclusive a organização do tempo, tendo em vista que ele precisa cumprir o prazo de entrega ele mesmo pode definir o cronograma de trabalho.

Outro aspecto mencionado como limitante foi a extensão do trabalho, ou seja, consideraram que a elaboração dos portfólios foi bastante trabalhosa, contendo muitas atividades, o que é possível constatar pelas respostas: “A grande extensão do trabalho, o tempo que devíamos administrar com o trabalho e nossas outras obrigações fora da escola” (E1). "A 
extensão do trabalho, a parte teórica da construção de cada filo e as diferentes espécies contidas e cada um deles" (E3). "Um dos pontos negativos foi a extensão do trabalho que acaba prejudicando a qualidade do trabalho, pois deixei para fazer poucos dias antes da data de entrega" (E4). "Achei o trabalho extenso e desafiador, pois além dos desenhos teve a parte da contextualização manuscrita" (E16). "A grande extensão do trabalho é algo negativo" (E17).

Nascimento e Rôças (2015), destacam que é necessário conceder às estudantes possibilidades de aprendizagem e é importante que elas se apresentem de forma dinâmica e criativa. O portfólio construído mostrou características próprias da aprendizagem de cada estudante e as diferentes formas de aprendizagem que podem emergir em uma atividade complexa que requer associação de conhecimentos.

Como mencionado anteriormente, a elaboração do portfólio, assim como as demais atividades pedagógicas que visam a emancipação intelectual, requer autonomia e a organização dos estudantes que precisam saber administrar seu tempo. Freire (1996, p. 105) destaca que: "A liberdade amadurece no confronto com outras liberdades, na defesa de seus direitos em face da autoridade dos pais, do professor, do Estado". Em outras palavras, o ato de educar requer oportunizar a liberdade dos estudantes para que se percebam como sujeitos ativos inseridos na sociedade, mas para isso a escola precisa proporcionar a formação integral desses estudantes.

Uma terceira subcategoria identificada dentre as limitações foi que os estudantes consideraram o portfólio como uma atividade muito complexa. Algumas respostas que ilustram tal constatação são: "Os textos eram grandes, tive que resumir e muitas vezes recorrer ao dicionário para descobrir o significado das palavras, muitas vezes não encontrei e recorri a professora” (E5). "O processo de construção do portfólio foi complexo, mas essencial para aprendermos mais sobre cada filo" (E8). "Achei a pesquisa complexa, mas aprendi as diferentes espécies de invertebrados que eu tratava como algo que não tinha necessidade e percebi que todos de certo modo tem uma importância para o meio ambiente" (E12)

Como destacam Carvalho e Porto (2005, p. 47), é essencial a criação de ambiente favorável para que os portfólios se desenvolvam em interação, participação e colaboração entre todos, interna e externamente aos espaços e tempos formais de aprendizagem. Essas limitações mencionadas para a realização da atividade servirão como subsídios para o planejamento de novas propostas de ensino. E, para tanto, precisam ser levadas em consideração, pois partem da própria avaliação de cada estudante. Assim, a avaliação por meio dos portfólios apresenta um aspecto subjetivo por isso é importante colher a opinião dos estudantes uma vez que a avaliação formativa busca avaliar todos os agentes envolvidos: professor, estudante, prática, entre outros.

A segunda categoria de análise refere-se as potencialidades do portfólio como estratégia 
de ensino. As respostas dadas aos três questionamentos intermediários $(4,5$ e 6$)$ permitiram identificar as seguintes subcategorias: facilita a compreensão do assunto, motiva a busca de informações e é uma avaliação diferenciada.

Uma primeira subcategoria identificada sobre as potencialidades dos portfólios, foi sobre a facilitação na compreensão sobre o assunto em estudo, no caso sobre os invertebrados. Seguem algumas expressões que ilustram essa constatação: "Por meio do trabalho foi possível conhecer os invertebrados, compreender seu funcionamento, e desenhando guardamos melhor ainda na memória." (E2). "O trabalho foi fundamental para eu compreender o assunto" (E9). "Ao realizar este trabalho eu concluí que os filos são de grande importância tanto para o homem quanto para a importância ecológica" (E12). "Com este trabalho consegui aprender sobre os animais invertebrados, sua importância e como interagem com a natureza" (E13). "Facilitou o conhecimento mesmo não tendo contato direto com cada filo, por meio do desenvolvimento de todo o trabalho eu consigo conhecer as características de cada filo” (E19).

As respostas acima confirmam a visão de Freire (1997) que preconiza que o educador precisa ampliar seus horizontes em relação a avaliação como uma atividade a ser repensada. $\mathrm{O}$ professor reflete sobre sua prática visando facilitar a compreensão do estudante no intuito de permitir que sejam agentes ativos diante do conhecimento. Cabe ressaltar que algumas respostas apontam aspectos relevantes acerca do aprendizado, onde os estudantes destacam a possibilidade de associar o conteúdo com relações ecológicas cotidianas.

Outro aspecto apontado pelos estudantes que se refere à potencialidade dos portfólios foi a possibilidade de aprender por meio da realização de pesquisas, o que pode ser constatado pelas seguintes afirmações: "Sei sobre os invertebrados por que eu pesquisei” (E6). "Todos os aspectos do trabalho foram importantes, a facilidade de poder obter conhecimento, mesmo sendo indiretamente não tendo contato em si com cada filo, a pesquisa me trouxe noções de cada filo" (E8). "Aprendi sobre cada processo dos invertebrados, fazendo minha pesquisa eu mesmo encontrei todas as informações" (E10). "O momento mais importante foi a pesquisa, pois quando eu pesquisava sobre o assunto descobria aspectos novos sobre os invertebrados" (E13). "Este foi um trabalho muito importante, porque ajuda na compreensão do reino, e a compreender o mundo dos animais, a evolução" (E18).

As repostas dadas pelos estudantes coadunam com o pensamento de Dias Junior (2014), que destaca que o professor tem um papel importante que consiste ao desafiar os estudantes para que produzissem os portfólios. Assim, os educandos passaram a buscar meios de realizar as pesquisas e elaborar os esquemas de forma autônoma. Por isso esta prática foge da aula tradicional e instiga o estudante ir ao encontro a construção do conhecimento. Para isso o 
professor precisa se reinventar e ser mediador do trabalho oportunizando ao aluno pesquisar e desvendar o tema sob os mais diversos prismas.

Uma terceira potencialidade mencionada é referente a elaboração dos portfólios ser utilizada como instrumento avaliativo, que, segundo os estudantes, caracteriza uma avaliação diferenciada em face das atividades avaliativas convencionais, predominantes nas outras aulas. Algumas respostas que ilustram tal constatação são: "Prefiro ser avaliada desta forma, acho uma avaliação mais justa” (E5). “Com o portfólio aprendi muitas coisas que eu nem imaginava e sequer sabia, se eu fosse fazer uma prova faria confusão entre os filos de invertebrados" (E9). "Foi uma ótima forma de avaliação, no meu ponto de vista" (E14). "O portfólio permitiu realizar minha auto avaliação de quanto eu aprendi a cada atividade, em cada assunto" (E16). "Foi uma ótima forma de avaliação, pois não fiquei ansiosa como nos dias de prova" (E8).

Com base nos estudos de Hadji (2001), é possível afirmar que a avaliação precisa ser uma intervenção intencional de leitura da realidade, por meio da qual o professor analisa conhecimentos e atitudes considerados coerentes que podem variar de acordo com a perspectiva da realidade dos estudantes. Alvarenga e Araújo (2006) defendem a utilização do portfólio como instrumento de avaliação que contribui para o desenvolvimento cognitivo dos estudantes.

A terceira e última categoria é referente as contribuições desse instrumento didático para a sistematização da aprendizagem dos invertebrados. Das respostas emitidas para os três últimos questionamentos emergiram as seguintes subcategorias: possibilidade de conhecer características dos invertebrados e facilitou a sistematização dos conhecimentos sobre os invertebrados.

Sobre a possibilidade de conhecer características dos invertebrados, algumas respostas foram selecionadas para evidenciar tal constatação: "Podemos realmente conhecer as características dos invertebrados, compreender seu funcionamento, e desenhando guardamos melhor ainda na memória" (E2). "A atividade ampliou o meu conhecimento sobre os invertebrados, e sua importância para o meio ambiente" (E5).

No estudo de Médici e Leão (2020), a metodologia empregada para possibilitar que os estudantes conhecessem as características dos invertebrados foi a modelização. Mesmo que a intervenção pedagógica proposta pelos autores tenha ocorrido com estudantes do Ensino Fundamental, os resultados positivos foram semelhantes. Ou seja, tanto a modelização quanto a elaboração dos portfólios são viáveis ao estudo dos seres vivos.

Sobre a facilitação do processo de sistematização dos conhecimentos, seguem as seguintes respostas: "Contribui para compreender o assunto de forma organizada, porque até então eu só sabia as características dos invertebrados" (E7). "Este trabalho ajudou na 
compreensão e esquematização do assunto, que envolve compreender o mundo dos animais e a evolução da vida" (E13). "Durante a pesquisa descobria detalhes que facilitaram compreender sobre cada filo dos invertebrados e a biodiversidade" (E17).

Ao analisar as respostas dadas pelos estudantes é possível compreender que estes conseguiram compreender o objetivo da atividade na construção de conhecimento e verificase, ainda, a satisfação dos estudantes por desenvolverem os portfólios. Conforme defende Fuentes-Rojas (2017), utilizar a elaboração de portfólios permite que o estudante se motive ao passo que é desafiado e isso se estende, inclusive, para a avaliação educacional.

\section{CONSIDERAÇÕES}

Esse texto teve como objetivo descrever uma experiência pedagógica que envolveu a elaboração de portfólios sobre invertebrados por estudantes do $2^{\circ}$ ano do Ensino Médio de uma escola pública mato-grossense, bem como a avaliação dos envolvidos acerca atividade didática. Isso mostrou que o uso do portfólio possibilita uma variação na forma de avaliar e, por isso, pode ser considerado uma alternativa viável para o ensino de ciências, possibilitando ao estudante autonomia no decorrer do processo formativo.

Dentre os critérios avaliados nos portfólios, merecem destaque os esquemas pictóricos utilizados que foram satisfatórios em 22 portfólios e o uso adequado de conceitos científicos que foram apresentados corretamente em 21 trabalhos. Por outro lado, apenas 13 portfólios apresentaram todas as fontes confiáveis. Já a capacidade reflexiva e forma de expressão (e apresentação) só foram consideradas totalmente adequadas em 14 portfólios.

Por meio da realização deste estudo, foi possível identificar as seguintes limitações na elaboração dos portfólios: pouco tempo para a elaboração do portfólio, a extensão do trabalho e o fato de 'elaboração de portfólio' ser considerada uma atividade muito complexa. Como potencialidades da atividade foram mencionadas: facilita a compreensão do assunto, motiva a busca de informações e é uma avaliação diferenciada. Quanto às contribuições que a atividade proporciona, os estudantes mencionam a possibilidade de conhecer características dos invertebrados e o quanto facilitou a sistematização dos conhecimentos sobre estes animais, sua evolução e suas interações ecológicas que são indispensáveis para o equilíbrio do planeta.

Assim sendo, este estudo se constitui em uma importante metodologia de ensino que permite variar as possibilidades para atender a demanda cada vez mais crescente nos debates de cunho pedagógico. Debates estes que apontam a diversificação de estratégias como um 
caminho viável a ser percorrido para construir aulas mais participativas, dialógicas e aprazíveis entre professores e estudantes.

\section{REFERÊNCIAS}

ALVARENGA, Georfravia Montoza; ARAUJO, Zilda Rossi. Portfólio: Conceitos básicos e indicações para utilização. Estudos em Avaliação Educacional, Fundação Carlos Chagas SP, v. 17, n. 33, jan./abr. 2006.

AMBRÓSIO, Márcia. O uso do portfólio no ensino superior. Editora Vozes Limitada, 2013.

ANASTASIOU, Léa das Graças Camargos et al. Estratégias de ensinagem. Processos de ensinagem na universidade. Pressupostos para as estratégias de trabalho em aula, v. 3, p. 67$100,2004$.

BACCI, Denise de La Corte. O uso do portfólio como instrumento de avaliação na disciplina Educação Ambiental na Educação Superior. In: X Encontro Nacional de Pesquisa em Educação em Ciências. X ENPEC, 2015, Água da Lindoia - SP. Anais dp X Encontro Nacional de Pesquisa em Educação em Ciências. X ENPEC, 2015.

BEHRENS, Marilda Aparecida. Paradigma da complexidade: metodologia de projetos, contratos didáticos e portfólios. Petrópolis, RJ: Vozes, 2006.

BOAS, Villas; DE FREITAS, Benigna Maria. O portfólio no curso de pedagogia: ampliando o diálogo entre professor e aluno. Educação \& Sociedade, v. 26, n. 90, p. 291-306, 2005.

CARVALHO, Marie Jane Soares; PORTO, Leonardo Sartori. Portfólio educacional: Proposta alternativa de avaliação: Guia didático. Porto Alegre: Editora da UFRGS, 2005.

CARVALHO, Silvia Helena Raimundo de. Avaliação na Educação Infantil: o portfólio como ferramenta. Revista Terra e Cultura, n. 44, ano 23, Janeiro a Julho, 2007, p.57-68.

COTTA, Rosângela Minardi Mitre; et al. Construção de portfólios coletivos em currículos tradicionais: uma proposta inovadora de ensino-aprendizagem. Ciência \& Saúde Coletiva, v. 17, n. 3, p. 787-796, 2012.

DIAS JUNIOR, Ronaldo. Portfólio: sua aplicabilidade na disciplina de Biologia. In: PARANÁ. Secretaria de Estado da Educação. Superintendência de Educação. Os Desafios da Escola Pública Paranaense na Perspectiva do Professor PDE. Curitiba: SEED/PR., 2014. V.1. (Cadernos PDE).

FUENTES-ROJAS, Marta. O portfólio como uma estratégia de aprendizagem na formação dos profissionais de saúde. Temas em Educ. e Saúde, Araraquara, v.13, n.1, p. 59-73, jan./jun. 2017. Disponível em: <https://doi.org/10.26673/rtes.v13.n1.jan-jun2017.5.9607>. Acesso em: 02 abr. 2020. 
GOMES, Andréia Patrícia; et al. Avaliação no Ensino Médico: o papel do portfólio nos currículos baseados em metodologias ativas. Revista Brasileira de Educação Médica (Impresso), v. 34, p. 390-396, 2010.

FREIRE, Paulo. Pedagogia da Autonomia - Saberes Necessários à prática educativa. São Paulo: Paz \& Terra, 1996.

FREIRE, Madalena; et al. Avaliação e planejamento: a prática educativa em questão. Instrumentos metodológicos II. São Paulo: Artcolor, 1997.

GONÇALVES, Fabiane Nunes; PACHECO, Daniela Fernandes; BITTENCOURT, Ricardo Luiz de. Uso do portfólio como instrumento de avaliação na educação superior. Revista Internacional de Formação de Professores, [S.1.], p. 209-221, jan. 2019.

HADJI, Charles. A avaliação desmistificada. Porto Alegre: ArtMed, 2001.

MÉDICI, Mônica Strege; LEÃO, Marcelo Franco. Modelização no ensino de ciências para promover aprendizados sobre os invertebrados. REVISTA REAMEC, v. 8, p. 455-476, 2020 .

NASCIMENTO, Lucilene Aparecida e Lima do; RÔÇAS, Giselle. Portfólio: uma opção de avaliação integrada para o ensino de ciências. Estudos em Avaliação Educacional. São Paulo, v. 26, n. 63, p. 742-767, set./dez. 2015.

SANTOS, Saulo; TERÁN, Augusto. Condições de ensino em Zoologia no nível fundamental: o caso das escolas municipais de Manaus -AM. Areté. Manaus. v. 06. p. 01-18, 2013.

VIEIRA, Vânia Maria de Oliveira. Portfólio: uma proposta de avaliação como reconstrução do processo de aprendizagem. Psicologia escolar e educacional, v. 6, n. 2, p. 149-153, 2002.

VIGOTSKY, Lev Semenovitch. A construção do pensamento e da linguagem. Tradução: Paulo Bezerra. - São Paulo: Martins Fontes, 2000.

Submetido em: 30 de junho de 2020.

Aprovado em: 02 de agosto de 2020. 